\title{
Erratum to: Allometric Models for Estimating Aboveground Biomass, Carbon and Nitrogen Stocks in Temperate Avicennia marina Forests
}

\author{
Richard H. Bulmer ${ }^{1}$ - Luitgard Schwendenmann ${ }^{2}$ - Carolyn J. Lundquist ${ }^{1,3}$
}

Published online: 2 March 2017

(C) Society of Wetland Scientists 2017

Erratum to: Wetlands

DOI 10.1007/s13157-016-0793-0

The canopy area calculation was incorrectly described in the methodology section of this paper. This calculation has now been corrected to: Canopy area $=\left(\left(\right.\right.$ canopy width $\left._{1} / 2\right) \times($ canopy width $\left.\left._{2} / 2\right)\right) \times \pi$.

The online version of the original article can be found at http://dx. doi.org/10.1007/s13157-016-0793-0

Richard H. Bulmer

bulmer.richard@gmail.com

1 Institute of Marine Science, University of Auckland, Auckland, New Zealand

2 School of Environment, University of Auckland, Auckland, New Zealand

3 National Institute of Water and Atmospheric Research Ltd (NIWA), Hamilton, New Zealand 